\title{
IDENTIFIKASI IBU BERSALIN KETUBAN PECAH DINI DENGAN KEJADIAN PARTUS PREMATURUS DI RSUD Dr. H.SOEWONDO KENDAL
}

\author{
Heny Rosiana ${ }^{1}$, Ana Sundari $^{2}$, Mimi Ruspita ${ }^{3}$ \\ 1,2,3UPP Kampus Kendal Poltekkes Kemenkes Semarang
}

\begin{abstract}
ABSTRAK
Ketuban pecah dini adalah keluarnya cairan dari jalan lahir sebelum proses persalinan.Insiden pecah ketuban secara spontan sebelum usia gestasi 37 minggu adalah sekitar 3-6\%. Sekitar 30-40\% persalinan premature didahului oleh pecah ketuban. Komplikasi ini merupakan faktor paling signifikan terhadap kemungkinan kelahiran premature. Hasil survey pendahuluan di RSUD Dr.H.Soewondo Kendal pada tahun 2012 terdapat 1231 ibu bersalin diruang VK. Dari jumlah tersebut diketahui 65 ibu bersalin mengalami persalinan premature yang disebabkan oleh ketuban pecah dini. Tujuan penelitian ini adalah untuk mengidentifikasi ibu bersalin ketuban pecah dini dengan kejadian partus prematurus di RSUD Dr.H.Soewondo KendalJenis penelitian yang digunakan adalah deskriptif. Subyek penelitian adalah semua ibu bersalin di RSUD Dr.H.Soewondo Kendal pada bulan Januari-Februari tahun 2013, didapatkan jumlah sampel sebanyak 419 responden. Kesimpulannya hasil penelitian ini adalah ibu yang mengalami persalinan KPD sebanyak 330 (78,8\%) dan ibu yang mengalami Partus Prematur sebanyak 116 (27,7\%).Saran bagi tenaga kesehatan agar memberikan pelayanan yang terbaik pada ibu bersalin yang mengalami KPD dan bayi yang lahir premature.
\end{abstract}

Kata kunci: KPD, Partus Prematur 


\section{PENDAHULUAN}

Insiden pecah ketuban secara spontan sebelum usia gestasi 37 minggu adalah sekitar 3-6\%. Sekitar 30-40\% persalinan premature didahului oleh pecah ketuban. Komplikasi ini merupakan faktor yang paling signifikan terhadap kemungkinan persalinan dan kelahiran premature. (Liu,2008,hal.162)

Pengelolaan ketuban pecah dini (KPD) merupakan masalah yang masih kontroversial dalam kebidanan.

Pengelolaan yang optimal dan yang baku masih belum ada, selalu berubah. KPD sering kali menimbulkan konsekuensi yang dapat menimbulkan morbiditas dan mortalitas pada ibu maupun bayi terutama kematian perinatal yang cukup tinggi. Kematian perinatal yang cukup tinggi ini diantaranya karena kematian akibat kurang bulan, dan kejadian infeksi yang meningkat karena partus tak maju, dan partus buatan yang sering dijumpai pada pengelolaan kasus KPD terutama pada pengelolaan konservatif.(Joseph,2001)

KPD merupakan komplikasi yang berhubungan dengan kehamilan kurang bulan dan memiliki kontribusi yang besar pada angka kematian perinatal pada bayi yang kurang bulan.(Elizabeth,2002)

Profil Dinas Kesehatan Propinsi Jawa Tengah melaporkan bahwa AKI di Jawa Tengah tahun 2008 adalah sebesar $714,42 / 100.000$ kelahiran hidup dan AKB sebesar 9,27/1000 kelahiran hidup. Berdasarkan laporan dinas kesehatan Kendal, AKI dari tahun 2007-2008 mengalami peningkatan. Jumlah kematian ibu tahun 2007 di Kabupaten Kendal sebesar 9 orang (AKI 63,13/100.000 kelahiran hidup) dan mengalami peningkatan tahun 2008 menjadi 23 orang (AKI 159,76/100.000 kelahiran hidup).

Dari 23 kematian tersebut 1 terjadi saat hamil, 17 saat persalinan(paling tinggi dibanding Kabupaten yang selain di Jawa) Berdasarkan pengalaman yang terjadi dilapangan peristiwa ketuban pecah dini sering menyebabkan partus premature. Banyak yang mengalami partus premature yang disebabkan oleh ketuban pecah dini diberbagai rumah sakit. Mereka umumnya sudah mengerti bahwa bila keluar air ketuban sebelum hari perkiraan lahir segera kerumah bidan dan tentunya bidan harus segera merujuk pasien ke RS dengan kasus KPD. 
Kebanyakan pasien yang mengalami yang digunakan adalah ibu bersalin kasus KPD ini umur kehamilannya kurang ketuban pecah dini.

dari 37 minggu. Dan kasus ini sering Variabel dependent adalah faktor yang terjadi di masyarakat yang social dan ekonominya rendah. Penyebab dari KPD bisa dari berbagai macam factor.

Hasil survey pendahuluan di RSUD Dr.H.Soewondo Kendal pada tahun 2013 terdapat 1231 ibu bersalin diruang VK. Dari jumlah tersebut diketahui ada 65 ibu bersalin yang mengalami persalinan premature yang disebabkan oleh salah satu faktor yaitu ketuban pecah dini. Dari hal tersebut peneliti tertarik untuk melakukan penelitian tentang," Identifikasi ibu bersalin ketuban pecah dini dengan kejadian partus prematurus di RSUD Dr.H.Soewondo Kendal”.

Tujuan umum untuk mengidentifikasi ibu bersalin ketuban pecah dini dengan kejadian partus prematur

\section{METODE PENELITIAN}

Variabel Independent adalah variabel bebas yang biasanya dimanipulasi, diamati dan diukur untuk diketahui hubungannya atau pengaruhnya terhadap variabel lain.(nursalam,2011, hal 97). Dalam penelitian ini variabel independen 
bersalin di RSUD Dr.H.Soewondo Kendal pada bulan Januari - Februari tahun 2013. Yaitu berjumlah 419 orang dengan sampel jenuh.

Kriteria adalah kriteria atau ciri-ciri yang perlu dipenuhi oleh setiap anggota yang dapat diambil sebagai sampel. (Notoatmodjo,2010,hal 130). Dalam penelitian ini kriteria inklusinya adalah semua lbu bersalin di RSUD Dr.H.Soewondo Kendal jumlah 419 orang. Kriteria eksklusi adalah ciri-ciri anggota populasi yang tidak dapat diambil sebagai sampel. (Notoatmodjo,2010,hal 37). Dalam penelitian ini kriteria eksklusinya adalah semua data lengkap pada buku register di RSUD Dr.H.Soewondo Kendal sehingga tidak ada kriteria eksklusinya.

Cara pengumpulan data dalam penelitian ini menggunakan data sekunder. Data sekunder adalah data yang diperoleh peneliti dari pihak lain.(Chandra,2008,hal 20).Dalam penelitian ini didapat dari buku register diruang VK RSUD Dr.H.Soewondo Kendal yang berisi no register,diagnosa dan umur kehamilan.

Proses pengumpulan data adalah sebagai berikut, setelah mendapatkan ijin peneliti mendatangi tempat penelitian

Midwifery Care Journal
Alat Penelitian dalam penelitian ini adalah pengumpulan data ini menggunakan observasi dokumentasi buku register yang ada di ruang VK (mawar) RSUD Dr. H.Soewondo Kendal dan alatnya adalah ceklis. Pengumpulan ini adalah semua ibu bersalin bulan Januari - Februari 2013.

Editing yaitu memeriksa data yang telah dikumpulkan baik berupa daftar pertanyaan, kartu atau buku register. Yang dilakukan pada kegiatan memeriksa data adalah menjumlah dan melakukan koreksi.(Budiarto,2001, hal 29). Dalam penelitian ini peneliti memeriksa kembali data yang telah didapat dalam buku register.

Coding yaitu kegiatan pemberian kode numeric (angka) terhadap data yang terdiri atas beberapa kategori. Pemberian kode ini sangat penting bila pengolahan dan analisis data menggunakan computer.(Hidayat,2012,hal 121).Dalam penelitian ini peneliti melakukan pemberian kode, KPD : Ya ; 1, Tidak ; 2 , partus premature : Ya ; 1, Tidak ; 2.

Tabulatingyaitu pengorganisasian data sedemikian rupa agar dengan mudah dapat dijumlah, disusun, dan didata untuk disajikan dan dianalisis. Proses tabulasi dapat dilakukan dengan berbagai cara 
antara lain dengan metode Tabel 1.1 Distribusi Frekuensi ibu bersalin tally,menggunakan kartu dan KPD Di RSUD Dr. H. Soewondo Kendal menggunakan computer. tahun 2013

(Budiarto,2001,hal 30). Dalam penelitian ini peneliti menggunakan metode SPSS 16,0 .

Tanpa nama (Anonimity) untuk menjaga kerahasiaan subjek, responden tidak mencantumkan nama dalam checklist pada lembar pengumpulan data, peneliti berusaha menuliskan kode berupa no urut 1-419 pada masing-masing lembar checklist.

Menjaga kerahasiaan (Confidentiality) keberhasilan informasi yang telah diberikan oleh subjek dijamin oleh penelitian.(Hidayat,2012,hal 93-95). Untuk menjaga kerahasiaan pasien maka peneliti hanya menuliskan no register saja.

\section{HASIL PENELITIAN DAN BAHASAN}

Hasil penelitian disajikan dalam 2 tingkatan yaitu analisis univariat yang menjelaskan dan mendiskripsikan karakter setiap variabel penelitian dan variabel bivariat yang menampilkan 2 variabel.

\begin{tabular}{ll}
\hline $\begin{array}{l}\text { Partus Frekuensi } \\
\text { Prematur }\end{array}$ & $\begin{array}{l}\text { Persentase } \\
(\%)\end{array}$ \\
\hline $\begin{array}{l}\text { Prematur } 116 \\
\text { Tidak } 214\end{array}$ & $27,7 \%$ \\
Prematur & $51,1 \%$ \\
\hline Jumlah 330 & $78,8 \%$ \\
\hline
\end{tabular}

Berdasarkan Tabel 1.2 diketahui bahwa yang mengalami kejadian partus premature sebanyak $116 \quad(27,7 \%)$ dan

Berdasarkan Tabel 1.1 diketahui bahwa yang mengalami KPD ada 330 (78,8\%) dan lainnya yang tidak mengalami KPD terdapat $89(21,2 \%)$ ibu bersalin.

Tabel 1.2 Distribusi Frekuensi ibu bersalin dengan kejadian partus premature pada ibu bersalin KPD di RSUD Dr. $\mathrm{H}$. Soewondo Kendal tahun 2013

Midwifery Care Journal 
yang tidak mengalami partus premature sebanyak $214(51,1 \%)$ ibu bersalin.

Tabel 1.3 Distribusi Frekuensi ibu bersalin dengan kejadian partus premature pada ibu bersalin tidak KPD di RSUD Dr. $\mathrm{H}$. Soewondo Kendal tahun 2013

Berdasarkan Tabel 1.4 diketahui bahwa ibu bersalin dengan KPD yang mengalami partus premature berjumlah 116 (27,7\%) orang, dan yang tidak mengalami partus premature berjumlah $214(51,1 \%)$ orang. Sedangkan ibu bersalin yang tidak KPD

\begin{tabular}{ll}
\hline $\begin{array}{l}\text { Partus Frekuensi } \\
\text { Prematur }\end{array}$ & $\begin{array}{l}\text { Persentase } \\
(\%)\end{array}$ \\
\hline Prematur 89 & $21,2 \%$ \\
Tidak 0 & $0 \%$ \\
Prematur & \\
\hline Jumlah 89 & $21,2 \%$ \\
\hline
\end{tabular}
yang mengalami partus premature berjumlah $89(21,2 \%)$ orang dan yang tidak KPD dan tidak premature berjumlah 0 orang.

Dari hasil analisa data yang diperoleh didapat ibu bersalin KPD yang mengalami partus premature berjumlah $116(27,7 \%)$

Berdasarkan Tabel 1.3 diketahui bahwa yang mengalami kejadian partus premature sebanyak $89(21,2 \%)$ dan yang tidak mengalami partus premature sebanyak $0(0 \%)$ ibu bersalin.

Tabel 1.4 Ibu bersalin KPD dengan kejadian partus premature di RSUD Dr. H. Soewondo Kendal tahun 2013 orang, dan yang tidak mengalami partus premature berjumlah $214(51,1 \%)$ orang. Sedangkan ibu bersalin yang tidak KPD yang mengalami partus premature berjumlah $89(21,2 \%)$ orang dan yang tidak KPD dan tidak premature berjumlah 0 orang.

Insiden pecah ketuban secara spontan sebelum usia gestasi 37 minggu adalah \begin{tabular}{llll}
\hline Ibu & Partus Prematur & Total & sekitar $3-6 \%$. Sekitar $30-40 \%$ persalinan \\
\cline { 2 - 4 } Kersalin & Ya & Tidak & Nilai $p$
\end{tabular} $\begin{array}{lllllllll}\mathrm{N} & \% & \mathrm{~N} & \% & \mathrm{~N} & \% & \text { Komplikasi ini merupakan faktor yang }\end{array}$ \begin{tabular}{llllllll}
\hline Ya & 116 & 27,7 & 214 & 51,1 & 330 & 78,8 & paling signifikan terhadap kemungkinan
\end{tabular}

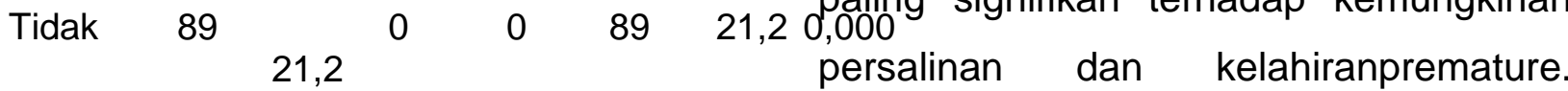

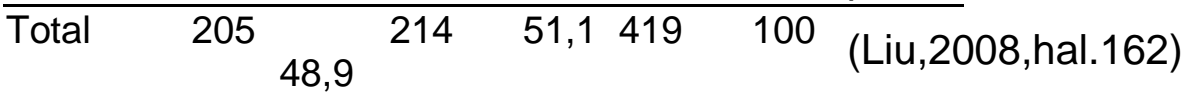


Berdasarkan analisa bahwa ibu bersalin KPD di RSUD Dr. H. Soewondo Kendal dapat mempengaruhi terjadinya partus prematur. Hasil penelitian ini sesuai dengan teori yang ada menyatakan bahwa ibu yang bersalin KPD salah satu komplikasinya adalah prematuritas dan partus premature komplikasinya salah satunya adalah KPD.

Penanganan KPD harus segera dilakukan jika tidak akan terjadi infeksi hal ini juga sesuai dengan teori(Marmi, Suryaningsih, Fatmawati,2011, hal 104106) yang menyebutkan bahwa komplikasi pada ibu diantaranya Infeksi intrapartal/dalam persalinan (Jika terjadi infeksi dan kontraksi ketuban pecah maka bisa menyebabkan sepsis yang selanjutnya dapat mengakibatkan meningkatnya angka morbiditas dan mortalitas) dan Infeksi puerperalis/masa nifas. Sehingga tak jarang janin yang belum cukup bulan harus segera dilahirkan. Persalinan premature menjadi penanganan serius karena bila bayi yang mengalami partus premature biasanya akan terjadi hipotermi dan mengalami hiperbilirubin hal ini sesuai teori (Ikatan Dokter Anak Indonesia,2004) yang menyebutkan komplikasi pada bayi yaitu diantaranya hipotermi dan hiperbilirubin Penanganan KPD di RSUD Dr. $\mathrm{H}$. Soewondo Kendal sudah sangat baik terbukti dengan cepatnya penanganan KPD dengan memberikan antibiotik agar tidak terjadi infeksi walaupun ibu mengalami partus premature. Hal ini sesuai teori dari (Prawirohardjo,2009,hal 219).

\section{KESIMPULAN}

Dari hasil penelitian tentang identifikasi ibu bersalin ketuban pecah dini dengan kejadian partus prematur di RSUD Dr. H. Soewondo Kendal tahun 2013 dan berdasarkan pengolahan data dapat diambil kesimpulan sebagai berikut: Persalinan KPD di RSUD Dr. $\mathrm{H}$. Soewondo Kendal sebanyak 330 (78,8\%) persalinan. Kejadian Partus Prematur di RSUD Dr. H. Soewondo Kendal sebanyak $116(27,7 \%)$ ibu. Ibu bersalin KPD yang mengalami partus premature berjumlah $116(27,7 \%)$ orang, dan yang tidak mengalami partus premature berjumlah $214(51,1 \%)$ orang. Ibu bersalin yang tidak KPD yang mengalami partus premature berjumlah $89(21,2 \%)$ orang dan yang tidak KPD dan tidak premature berjumlah 0 orang. 
Dari hasil penelitian tentang identifikasi ibu bersalin ketuban pecah dini dengan kejadian partus prematur di RSUD Dr. $\mathrm{H}$. Soewondo Kendal tahun 2013 dan berdasarkan pengolahan data maka diharapkan bagi bidan agar memberikan pertolongan yang cepat dan tepat pada ibu yang KPD sehingga akan mengurangi bahaya infeksi dengan jalan merujuk ke Rumah Sakit.

\section{DAFTAR PUSTAKA}

1. Anonymous.Air ketuban.Diakses tanggal 4 Agustus 2011 (terakhir diubah tanggal 23 Mei 2012 jam 10.45 WIB). Didapat dari: http://www.air ketuban.com

2.

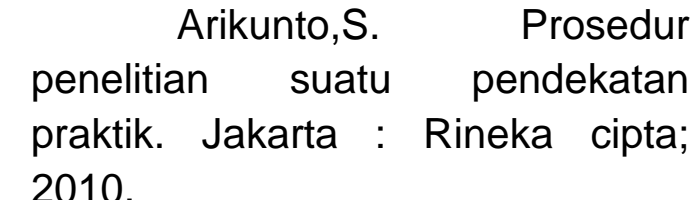

3. Astuti Wahyu Dwi,Sholikhah Hidayat Heni,Angkasawati Tri Juni.Estimasi resiko penyebab kematian neonatal di Indonesia tahun 2007.diakses tanggal 13 Oktober. Didapat dari: http//id.shooving.com/medicine and health

4. Bruce Elizabeth.Premature rupture of membrane (PROM). Diakses tahun 2002. Didapat dari:

Midwifery Care Journal http://www.compleatmother.com/fro m.htm

5. Budiarto Eko. Biostatika untuk kedokteran dan kesehatan masyarakat. Jakarta : EGC; 2001.

6. Chandra Budiman. Metodologi penelitian kesehatan. Jakarta : EGC; 2008.

7. Hidayat A.Alimul. Metode penelitian keperawatan dan teknis analisis data. Jakarta : Salemba medika; 2007.

8. Ikatan Dokter Anak Indonesia (IDAI). Bayi Berat Lahir Rendah.Dalam standar pelayanan medis kesehatan anak.Edisi I.Jakarta; 2004. Didapat dari: http://www.kuliahbidan.com

9. Liu,David T.Y. Manual persalinan. Edisi ketiga. Jakarta : EGC; 2008.

10. Manuaba, Ida Bagus Gede. IImu kebidanan penyakit dan keluarga berencana untuk pendidikan bidan. Jakarta : Buku Kedokteran; 1998.

11. Marmi, Suryaningsih A.Retno Murti dan Fatmawati Ery. Asuhan kebidanan patologi, Yogyakarta. Pustaka Pelajar; 2011.

12. Mochtar Rustam. Sinopsys obstetri. Edisi ketiga. Jakarta : Buku kedokteran; 1998.

13. Notoatmodjo Soekitdjo. Metodologi penelitian kesehatan. Jakarta : Rineka Cipta; 2010.

14. Prasetyawati Arsita Eka.Kesehatan ibu dan anak (KIA). Yogyakarta: Muha media; 2012.

15. Prawirohardjo. Sarwono,Buku Acuan Nasional Pelayanan 
Kesehatan Maternal Dan Neonatal, Jakarta : YBP-SP, 2009.

16. Rukiyah, Yulianti. Asuhan Kebidanan IV (Patologi Kebidanan), Jakarta : Trans Info Media,2010

17. Smith Joseph J.Premature of membranes. Diakses tahun 2001.
Didapat

dari:

http://www.chclibrary.org/micromed 100061770.

18. Subramanian KS.Low birth weigh infant.Naskah masuk tanggal 25 September 2006.Diakses tanggal 11 Desember 2007. Didapat dari: 